in $19 \%$, and were absent in $11 \%$. At final follow-up, only $43 \%$ foci were occipital, $46 \%$ extraoccipital, and absent in $11 \%$. A family history of epilepsy was identified in 12 patients (32\%), including a family with 2 children having BOSSS. Febrile convulsions preceded onset of BOSSS in 14 (38\%). Total number of BOSSS seizures was 1 - 27 (median 5). Status epilepticus occurred in 22 (59\%). Remission for longer than 2 years was achieved in $28(76 \%)$; and $80 \%$ of these remitted by 3 years after onset. Antiepileptic drugs had been discontinued in 21 (57\%). Fifteen children (40\%) with recurrent prolonged seizures, initially refractory to AEDs, had an earlier onset and more frequent complications. Seizures remitted by 12 years in all cases. (Oguni H, Hayashi K, Funatsuka M, Osawa M. Study on earlyonset benign occipital seizure susceptibility syndrome. Pediatr Neurol October 2001;25:312-318). (Respond: Dr Hirokazu Oguni, Department of Pediatrics, Tokyo Women's Medical University, 8-1 Kawada-cho, Shinjuku-ku, Tokyo 162, Japan).

COMMENT. The clinical features of early-onset BOSSS vary from a single or occasional seizure to cases with recurrent prolonged seizures, initially AED resistant, and even status epilepticus in more than half the patients, despite ultimate remission by 12 yeare of age. Datients with prolenged scizurcs, initially resistant to $\mathrm{AED}$, are recognized by an earlier onset and more frequent complications (prematurity with asphyxia, neonatal seizure, borderline IQ). The authors propose that the term occipital be removed from the terminology, since patients meeting all other criteria for BOSSS may have extraoccipital EEG spike foci or sometimes no EEG epileptic foci.

\title{
OPTICAL FILTERS FOR TV-INDUCED PHOTOSENSITIVE EPILEPSY
}

Two different types of optical filters were tested in 20 photosensitive epileptic patients for ability to inhibit photoparoxysmal response (PPR) and seizures, in a study at Gifu Prefectural Gifu Hospital, Japan. One filter reflected long-wavelength red light selectively (wavelength dependent) and the other absorbed light in the visible spectrum evenly (quantity of light-dependent). Both filters individually provided insufficient inhibition of PPR $(<50 \%)$ while using conventional strobe intermittent photic stimulation (IPS), whereas compound filters (both types) inhibited PPR by $90 \%$ for IPS and $95 \%$ for photic stimulation using cathode ray tubes (CRT). Compound optical filters do not block the chromaticity of emissions from TV-CRT, and may be used to prevent TV-induced seizures in nhotosensitive nersons. (Takahashi $Y$ Sato $T$, fotn $K$, et al. Dotical filtore inhibiting teievision-induced photosensitive seizures. Neurology November ( 2 of 2) 2001;57:1767-1773). (Reprints: Dr Yukitoshi Takahashi, Department of Pediatrics, Gifu Prefectural Gifu Hospital, 4-6-1 Noishiki Gifu 500-8717, Japan).

COMMENT. The use of optical filters to prevent photosensitive epilepsy is not a novel suggestion. Glasses with a neutral filter were introduced some 50 years ago by Bickford RG et al (Am I Dis Children 1953;86:170) at the Mayo Clinic. The use of compound filters may lessen the risk of seizures or epilepsy onset in persons with latent photosensitivity when viewing TV or using personal computers. Photosensitivity is a common problem affecting 4 to $9 \%$ of the population. It has an autosomal dominant inheritance and a strong age-dependent penetrance. In recent years, the incidence of photosensitive reflex epilepsy has escalated as an environmental hazard, mainly associated with the introduction of electronic devices, particularly video games. A mass seizure outbreak in Japan was caused by an animated TV program for children, 'Pocket Monsters'. (Erba G. Preventing seizures from "Pocket Monsters." A way to control reflex epilepsy. Editorial, Neurology Nov (2 of 2) 2001;57:1747-1748). The onus for prevention should be 
placed more on the manufacturer of hazardous video games and regulatory agencies than on the consumer, however.

\section{HOT WATER EPILEPSY}

The clinical and electroencephalographic features of 21 patients with hot water epilepsy (HWE) have been analysed at the University of Istanbul, Turkey. The male:female ratio was 3:1. Age at onset of seizures ranged from 19 months to 27 years (mean, 12 years). Seizures were precipitated by pouring water over the head in 14 cases or by bathing in hot water. Nine expressed a pleasurable feeling during the seizures. Seizures were partial in 20 , with secondarily generalized in 8 , and generalized in 1 . Spontaneous seizures also occurred in $62 \%$. EEGs were abnormal in 8, with focal temporal epileptiform discharges. Neuroimaging was normal in 12 patients studied. Seizures were controlled by avoiding hot water in 7 patients. One patient who induced seizures compulsively was treated with carbamazepine (CBZ). The remaining patients responded to $\mathrm{CBZ}$ or valproate. (Bebek N, Gurses C, Gokyigit A et al. Hot water epilepsy: clinical and electrophysiologic findings based on 21 cases. Epilepsia Sept 2001;42:1180-1184). (Reprints: Dr C Gurses, University of Istanbul, Istanbul Faculty of Medicine/Dept Neurology, Millet cad 34390 Capa-Istanbul, Turkey).

COMMENT. Hot water epilepsy (HWE), a rare form of reflex epilepsy, has a male preponderance, may be self induced, often for pleasure, and shows temporal lobe localization of EEG epileptiform discharges. It is generally self-limited, controlled by avoiding hot water-head baths or showers, but antiepileptic medication is sometimes required.

HWE is a regional religious custom in Southern India, where 279 patients were studied between 1980-83. Ages ranged from 8 mos to 58 years, $28 \%$ below 6 years. Only $7 \%$ had febrile convulsions. Complex partial seizures occurred in $67 \%$ and generalized tonic-clonic seizures in 33\%. Spontaneous seizures also occurred in $30 \%$. A positive family history of epilepsy was obtained in $22 \%$ and for HWE in only 7\%. (Satishchandra P et al. Epilepsia 1988;29:52-56). See Progress in Pediatric Neurology I, PNB Publishers, 1991;pp43-44.

\section{VIGABATRIN-ASSOCIATED VISUAL FIELD DEFECTS}

The prevalence, risk factors, and long-term outcome of vigabatrinassociated visual field defects were examined in 60 adult patients with partial epilepsy treated with vigabatrin for 7 months to 14 years at the University of Kuopio Hospital, Finland. At first examination, bilateral concentric defects occurred in $24(40 \%)$ of 60 patients; they were severe in $8(13 \%)$, and a mild constriction in 16 (27\%). Repeated kinetic Goldmann perimetries and follow-up examination performed after 4 to 38 months (mean, 15 mos) in 55 patients ( 29 having discontinued therapy) revealed no reversion or progression in visual field constriction. (Nousiainen I, Mantyjarvi M, Kalviainen R. No reversion in vigabatrin-associated visual field defects. Neurology Nov (2 of 2) 2001;57:19161917). (Reprints: Dr liris Nousiainen, Department of Ophthalmology, Kuopio University Hospital, POB 1777, 70211 Kuopio, Finland).

COMMENT. The age of the patients and high cumulative doses of vigabatrin employed could be risk factors for the poor outcome and severe limiting effect on daily activities in adults. In a young patient, recovery of visual fields has been reported after early withdrawal of vigabatrin (Giordano L et al. Neurol Sci 2000;21:185-186). Duration of vigabatrin treatment (but not the dose or age of child) was correlated with visual field constriction in $65 \%$ of 17 children 